\title{
A Validated Tool for Psychiatric Comorbidity in the Patients With Functional Dyspepsia: Author's Reply
}

TO THE EDITOR: Studies on psychometric properties of screening questionnaires in chronic medical conditions are often criticized for their limited generalizability. ${ }^{1}$ The reason is obvious, as most studies are conducted in referral centres where referral bias is unavoidable. ${ }^{2}$ This might contribute to the high prevalence of psychiatric illness in our sample. ${ }^{3}$ This suggestion could be also observed by similar results in other studies. ${ }^{4-6}$ On the other hand, it is often difficult to make confirmed diagnosis of functional dyspepsia in primary care setting where endoscopic examination is not widely available. In addition, gold standard Structured Clinical Interview is difficult to be implemented in large scale, because as trained clinicians are needed to conduct this lengthy assessment in this process. In order to tackle this dilemma, one of the solutions is to conduct a population-based study, using 12-item General Health Questionnaire by general practitioners and family physicians before they refer their patients with functional dyspepsia for thorough psychiatric assessment. We hope to audit the appropriateness of this 12-item General Health Questionnaire as a screening tool in primary care setting.
1. Lee JC, Hong SJ. A validated tool for psychiatric comorbidity in the patients with functional dyspepsia. J Neurogastroenterol Motil 2010;16:221.

2. Hartman JM, Forsen JW Jr, Wallace MS, Neely JG. Tutorials in clinical research: part IV: recognizing and controlling bias. Laryngoscope 2002;112:23-31.

3. Tse AW, Lai LH, Lee CC, et al. Validation of self-administrated questionnaire for psychiatric disorders in patients with functional dyspepsia. J Neurogastroenterol Motil 2010;16:52-60.

4. Haug TT, Svebak S, Wilhelmsen I, Berstad A, Ursin H. Psychological factors and somatic symptoms in functional dyspepsia. A comparison with duodenal ulcer and health controls. J Psychosom Res 1994;38:281-291.

5. Mine K, Kanazawa F, Hosoi M, Kinukawa N, Kubo C. Treating nonulcer dyspepsia considering both functional disorders of the digestive system and psychiatric conditions. Dig Dis Sci 1998;43: 1241-1247.

6. Guz H, Sunter AT, Bektas A, Doganay Z. The frequency of the psychiatric symptoms in the patients with dyspepsia at a university hospital. Gen Hosp Psychiatry 2008;30:252-256.

Conflicts of interest: None.

Larry H Lai, MRCP(UK), FHKCP Ada WY Tse, MRCPsych, FHKCPsych ${ }^{2}$ Justin $\mathrm{CY}$ Wu, MD, FRCP ${ }^{1}$

${ }^{1}$ Institute of Digestive Disease The Chinese University of Hong Kong Hong Kong SAR, China ${ }^{2}$ Kwai Chung Hospital, Hospital Authority Hong Kong SAR, China 